This item was submitted to Loughborough's Research Repository by the author.

Items in Figshare are protected by copyright, with all rights reserved, unless otherwise indicated.

\title{
Absorption coefficient modified pressed powders for calibration of laser ablation inductively coupled plasma mass spectrometry
}

PLEASE CITE THE PUBLISHED VERSION

\section{PUBLISHER}

(C) RSC Publishing

\section{LICENCE}

CC BY-NC-ND 4.0

\section{REPOSITORY RECORD}

O'Connor, Ciaran, Mark R. Landon, and Barry L. Sharp. 2019. "Absorption Coefficient Modified Pressed Powders for Calibration of Laser Ablation Inductively Coupled Plasma Mass Spectrometry". figshare. https://hdl.handle.net/2134/2813. 
This item was submitted to Loughborough's Institutional Repository by the author and is made available under the following Creative Commons Licence conditions.

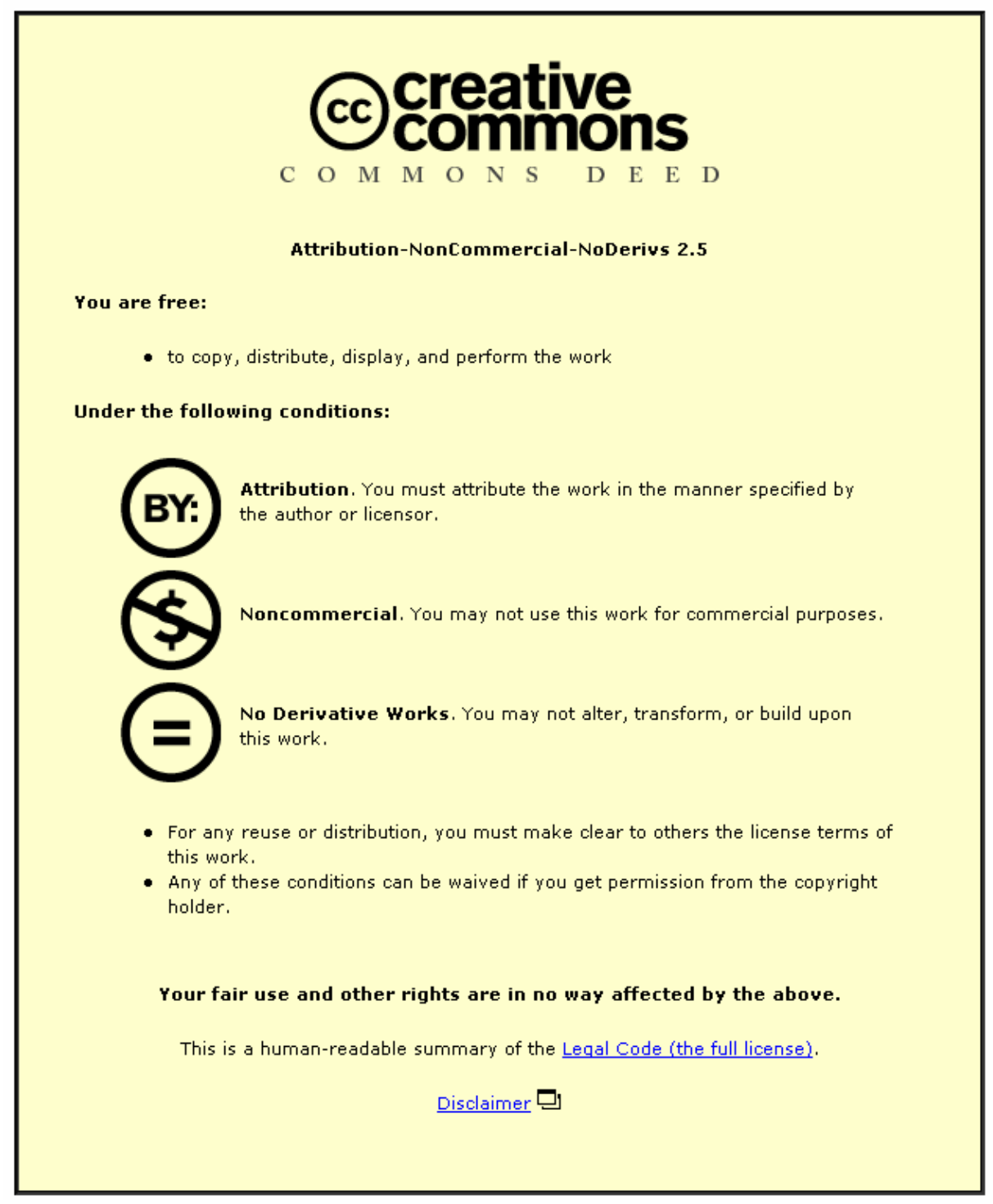

For the full text of this licence, please go to: http://creativecommons.org/licenses/by-nc-nd/2.5/ 


\title{
Absorption Coefficient Modified Pressed Powders for Calibration of Laser Ablation Inductively Coupled Plasma Mass Spectrometry
}

\author{
Ciaran O' Connor, ${ }^{a}$ Mark R. Landon ${ }^{a}$ and Barry L. Sharp ${ }^{\mathrm{a}^{*}}$ \\ ${ }^{a}$ Analytical Atomic Spectroscopy Group, Department of Chemistry, Loughborough \\ University, Loughborough, Leicestershire, LE11 3TU, UK \\ *E-mail: b.l.sharp@lboro.ac.uk; Tel: 01509222572
}

\begin{abstract}
Powdered samples have been pressed, utilising a standard $\mathrm{KBr}$ infrared (IR) press, to produce mechanically stable $13 \mathrm{~mm}$ discs. Three 'absorbing', organic based binders have been employed in this work; vanillic acid, pyrazinoic acid and nicotinic acid, chosen because of their high optical absorbance at the wavelength of the incident laser energy (213 nm). Poly(vinyl alcohol) (PVA) was employed as an example of a 'nonabsorbing' binder and because its use has been described previously in the literature. Discs of various sample/binder compositions were prepared, and their absorption properties characterised by diffuse reflectance spectroscopy. Laser Ablation Inductively Coupled Plasma Mass Spectrometry (LA-ICP-MS) was used to investigate the effect of different sample/binder compositions on signal sensitivity; whilst surface profilometry was performed on the resulting tracks to provide an estimate of the ablation depth achieved by the laser beam. It was found that discs prepared with vanillic acid had the highest optical absorbance at the wavelength of the laser system employed, resulting in a lower ablation depth and improved signal sensitivity probably through the formation of smaller particles during the ablation process.
\end{abstract}

Analysis of certified reference materials (CRMs) was performed using simple external calibration standards of similar and dissimilar CRMs. It was found that discs produced using a $40 \%$ vanillic acid binder, $60 \%$ sample composition gave superior quality analytical data when compared to the use of $40 \%$ PVA binder or no binder at all. These findings indicate the potential for good quality analytical data to be obtained when employing external calibration standards, without internal 
standardisation and without exact matrix matching. These data also provide further evidence that standardisation of ablation conditions and mass flux to the plasma are pre-requisites for robust calibration, particularly in the absence of a suitable internal standard element. 


\section{Introduction}

Laser Ablation Inductively Coupled Plasma Mass Spectrometry (LA-ICP-MS) has become the most versatile technique for the direct determination of trace elements in a wide variety of solid sample types. It has particular application for the determination of trace elements in sample types, such as metals, rocks, polymers and ceramics, and avoids the risk of contamination associated with complex digestion procedures.

The limitations of LA-ICP-MS are well known; namely elemental fractionation and a lack of certified reference materials (CRMs) for the majority of sample types. 'In house' solid synthetic standards are often prepared to allow external calibration; however, with such external standards it is especially important that the standard matches the sample in terms of matrix composition, since even a small difference in composition can lead to vastly different rates of ablation.

There are two common approaches to solid standard preparation. The first approach is fusion to form a glass bead or disc. ${ }^{1-9}$ The second approach is to press a powdered sample into a disc. ${ }^{2-4,7,10-21}$ These studies have shown that since the ablation yield can vary by as much as $50 \%$ between discs, poor analytical data is obtained unless the calibration standards are prepared to exactly match the sample, or an internal standard element is used to correct for these large differences in ablation yield.

A major advantage of standard preparation of this type is that it facilitates addition of internal standard elements, isotope spikes, or matrix modifiers. The use of matrix modifiers has been demonstrated by Boue-Bigne $e t$ al. ${ }^{22}$ to improve the analytical data obtained from the direct ablation of liquid calibration standards. The absorption coefficients of the standards were modified by the addition of organic chromophores so that they more closely matched those of the sample.

Matrix modification to improve the ablation efficiency has been achieved by addition of metal oxides in order to enhance the absorbance characteristics of the target. ${ }^{23-25}$ Weis et al. ${ }^{25}$ reported an extensive investigation into the addition of $\mathrm{Fe}_{2} \mathrm{O}_{3}$ as a matrix modifier to modify the absorption coefficient of lithium metaborate discs. It was found that the addition of $\mathrm{Fe}_{2} \mathrm{O}_{3}$ led to a greater absorption of the incident laser 
energy, leading to a shorter optical penetration depth and a subsequent reduction in the size of particles produced by the ablation process. Lee et al. ${ }^{21}$ found that the addition of Triton-X to samples pressed into discs led to increased sensitivity and suggested that this might be due to improved absorption of the laser energy.

Much work has been performed relating LA parameters to the particle size distribution of the generated aerosol and the effect upon figures of merit for ICP-MS. The parameters that have been investigated include; fluence, pulse duration, wavelength, carrier gas and absorption properties of the sample. ${ }^{25-39}$. However, it is important to understand that the particle size distribution created by the ablation process is not indicative of what reaches the ICP, since particles can change shape by processes such as vaporisation, condensation and agglomeration with other particles. ${ }^{40}$ The processes involved in the formation of particles from ablated matter are complex and remain poorly understood; however recent models, provided by Hergenroder, ${ }^{41-43}$ have helped to clarify this complexity, and provide explanations for the different particle size fractions encountered.

This work reports a detailed investigation into the benefits of the addition of organic chromophores, simultaneously acting as binders, to powdered samples before subsequent pressing into discs. The organic chromophores chosen for this investigation, vanillic acid, pyrazinoic acid and nicotinic acid, are common Matrix Assisted Laser Desorption Ionisation (MALDI) matrices and were chosen due to their high absorbance at $213 \mathrm{~nm}$, the wavelength of the laser ablation system employed. The other binder investigated in this work, poly(vinyl alcohol) (PVA), was chosen since it, and other high molecular weight alcohols and polymers, have been reported to act as effective sample binders. ${ }^{16,44-48}$ Further, PVA is relatively non-absorbing in comparison to the 'absorbing' binders at the laser wavelength. The molecular structures of all four binders are shown in Figure 1; whilst Table 1 lists their $\lambda_{\max }$ values and associated molar absorptivities. ${ }^{49}$

The addition of chromophores should improve the coupling between the laser beam energy and the sample, leading to an improved efficiency of ablation and the formation of smaller particles at the ablation site. The smaller particles are more efficiently transported to, and more fully processed by the plasma, leading to 
enhanced sensitivity and a reduction in elemental fractionation. It was anticipated that by incorporating the chromophores into the discs a more sample independent ablation process would result, offering the possibility of improved analytical data when using external calibration standards. This is of particular importance when no suitable internal standard is available. 


\section{Experimental}

\section{Solid Sample Preparation}

The powdered sample, in this case a certified reference material, and the powdered binder: PVA (Fisher Scientific, Loughborough, Leicestershire, UK), vanillic acid, pyrazinoic acid or nicotinic acid (Alfa Aesar, Heysham, Lancashire, UK), were weighed out to yield a combined total mass of $0.40 \mathrm{~g}$.

Two methods were employed for mixing of the two powders. The first was to simply combine the powders in a pestle and mortar and grind for a period of 10 min until a homogenous looking mixture was achieved. The second approach involved the use of a MM 200 mixer mill (Retsch, Leeds, Yorkshire, UK) to obtain a more homogenous mixture. In this case, the mixture was weighed out directly into a $25 \mathrm{ml}$ polystyrene sample vial with two, $9 \mathrm{~mm}$ polyamide beads. The mixture was homogenised for a period of $15 \mathrm{~min}$ at a frequency of $30 \mathrm{~Hz}$.

$0.25 \mathrm{~g}$ of the resulting mixtures of sample and binder were transferred to a standard infrared (IR) press using $13 \mathrm{~mm}$ dyes (Specac, Orpington, Kent, UK) and pressed into a disc using 10 tonnes of pressure for approximately $5 \mathrm{~min}$. The resulting discs had a diameter of $13 \mathrm{~mm}$ and a thickness of $1.2 \mathrm{~mm}$. This method of pressing produced discs of good mechanical stability and of good surface finish, as can be seen in Figure 2 , especially as the ratio of binder to sample was increased.

Early trials with PVA suggested that particle sizes of $<50 \mu \mathrm{m}$ were required for good ablation performance. The particle sizes used in this investigation were much smaller than this and were mostly in the $1-10 \mu \mathrm{m}$ range, which is the range produced by the mixer mill (values taken from manufacturers specification for milling of soft powders).

\section{Instrumentation}

Table 2 lists experimental parameters for all instrumentation used throughout this investigation. 
A commercially available UP-213 Laser Ablation System (New Wave Research Inc., Huntingdon, Cambridgeshire, UK) operating in the deep UV (213 nm) was employed using $\mathrm{He}$ as a carrier gas due to its improved ablation and transport characteristics. ${ }^{29}$, 50, 51 The He carrier gas was combined with an auxiliary Ar gas flow $1 \mathrm{~m}$ before the torch using a simple polypropylene 'Y'-piece (Fisher Scientific, Loughborough, Leicestershire, UK). A further tangential mixing vessel was placed in the Peltier chamber of the ICP-MS to facilitate further mixing of the two gas lines. All gas lines used were constructed from $1 \mathrm{~m}$ lengths of $6 \mathrm{~mm}$ O.D. Tygon ${ }^{\mathrm{TM}}$ tubing (Fisher Scientific, Loughborough, Leicestershire, UK).

The LA system was coupled to a VG PQ ExCell ICP-MS instrument (Thermo Electron Corporation, Winsford, Cheshire, UK). Optimisation of the torch-box position, lens voltages, auxiliary Ar gas flow, and LA carrier gas flow was performed before analysis, with respect to the ${ }^{115}$ In signal intensity obtained upon ablation of NIST 612 Trace Elements in Glass CRM. The LA parameters employed were used to reproduce the typical conditions encountered in bulk analysis by LA-ICP-MS.

Calibration experiments were performed both under 'dry' and 'wet' plasma conditions and the quality of analytical data compared to determine whether the more standardised plasma conditions offered by employing a 'wet' plasma led to an improvement in data quality, as has been previously reported. ${ }^{52}$ In this paper the term "wet" refers to a plasma in which the liquid phase aerosol and vapour phase water are present, i.e. the classical wet plasma produced in solution analysis. This was achieved by combining the aerosol produced by solution nebulisation of $18.2 \mathrm{M} \Omega \mathrm{cm}^{-1}$ purity water (Elga Lab Water, High Wycombe, Buckinghamshire, UK) using a PFA-100 $\mu \mathrm{L}$ Fixed Capillary Nebuliser (Elemental Scientific Inc., Omaha, Nebraska, USA) and custom made cyclonic spray chamber, with the LA aerosol using the polypropylene 'Y'-piece (Fisher Scientific, Loughborough, Leicestershire, UK). Figure 3 shows the experimental arrangement employed.

Diffuse Reflectance analysis was performed on the discs to characterise their absorption properties. For the purpose of this investigation it was the reflectance of the discs at $213 \mathrm{~nm}$ that was of particular relevance since this coincided with the 
wavelength of the LA system employed. An Ocean Optics (Dunedin, Florida, USA) photo-diode array spectrometer operated in diffuse reflectance mode was employed.

Surface profiling of the craters produced was performed using a custom made system employing a Rodenstock RM 600 laser stylus (Munich, Germany). This is a noncontact laser stylus that uses dynamic focusing of the laser beam and the focus error signal to determine surface topography.

\section{Homogeneity Trials}

In order to perform bulk analysis by LA-ICP-MS it is vital that the analyte is homogenously distributed throughout the sample. This is of particular importance when a binder is used, whether it is absorbing or not. For this reason an investigation into the homogeneity of the elemental distribution was performed, utilising the Transient Rapid Analysis (TRA) function of the ICP-MS. A dry plasma was used for this investigation.

Using the setup described in Figure 3 and the parameters listed in Table 2, the distributions of elements within discs produced by mixing in a pestle and mortar and discs produced by mixing in a MM 200 mixer mill were compared. For this investigation, three discs were analysed, consisting of GBW 07311 Sediment CRM and a vanillic acid binder. Their composition and mixing method is shown Table 3 .

${ }^{13} \mathrm{C}$ was used as an internal standard element to correct for differences in rates of ablation during the ablation of each track. The elemental distribution across the discs was monitored and the \%RSD of the ratio of analyte signal intensity to ${ }^{13} \mathrm{C}$ signal intensity was determined and used as an indication of homogeneity. The \%RSD was determined over a range of $9 \mathrm{~mm}$ in the middle of the laser ablated track i.e. between the $3 \mathrm{~mm}$ and $12 \mathrm{~mm}$ points on the graphs produced.

\section{Effect of Varying Disc Composition}

Discs of varying composition were produced to determine the effects of different types and compositions of binders and samples. Three different 'absorbing binders' were chosen for this investigation due to their high absorptivity around the 
wavelength of the incident laser beam, as shown in Table $1:^{49}$ vanillic acid, nicotinic acid and pyrazinoic acid. PVA was chosen as an example of a 'non-absorbing' binder. GBW 07311 Sediment CRM was chosen as a sample in this particular investigation, since it is well characterised for a range of analytes. A series of discs with increasing CRM composition i.e. $0,10,20,40,60,80$ and 100\% was produced for each combination of sample and binder.

\section{LA-ICP-MS Analysis}

These discs were analysed by LA-ICP-MS, using the parameters described in Table 2 and the setup shown in Figure 3, to determine the effects of differing binder type and binder composition on signal sensitivity and stability and to establish the optimum disc composition. In each case the laser beam was focused upon the disc surface. Response curves were plotted for all the isotopes monitored.

It should be noted that although the concentration of $\mathrm{C}$ was around $50 \%$ in the discs, the ablated mass produced by the UP-213 LA system was so small that no significant deposition was observed upon the cones, even in bulk analysis mode. For this reason no $\mathrm{O}_{2}$ addition to the plasma was required.

\section{Diffuse Reflectance Analysis}

Diffuse Reflectance analysis was performed, employing the parameters described in Table 2, on the same series of discs used for the LA-ICP-MS investigation, to determine the effect of differing binder type and binder composition on the absorption properties of the discs. The mean \% reflectance at $213 \mathrm{~nm}$ was determined for each disc using five replicates. All reflectance measurements were made relative to a PTFE diffuse reflectance standard as stated in Table 2.

The absorption properties of the pure binders were characterised by determining the mean \% reflectance of ' $100 \%$ blank' discs, with respect to the PTFE standard. 


\section{Surface Profilometry}

Surface profilometry was performed on the discs produced from $100 \%$ of each of the binders to determine the maximum ablated crated depth, produced using the same LA parameters as described in Table 2. This crater depth was used as an indication of the effective ablation depth achieved by the laser. It is recognised that optical absorbance was not the sole parameter affecting the data obtained in this investigation, and that the different physicochemical properties of the binders also affected the outcomes. However, the particle sizes of the binders used to press the discs were all similar and the press has been shown to produce discs of consistent density and hardness, so it was reasonable to assume that absorbance was the major factor determining the depth of the craters ablated.

\section{Calibration}

To determine whether the presence of the organic chromophore offered any advantage when performing quantitative analysis by LA-ICP-MS, two simple calibration strategies based upon external calibration with and without internal standardisation were devised.

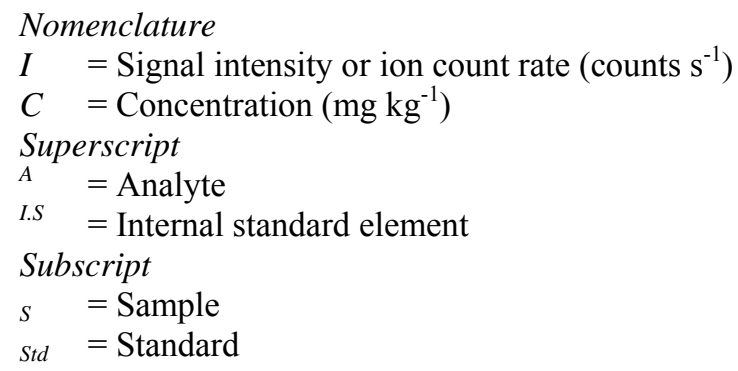

The concentration of analyte within the sample disc is determined from:

$$
C_{s}^{A}=I_{s}^{A} / \frac{I_{s t d}^{A}}{C_{S t d}^{A}}
$$

If an element of known concentration is available within the sample and standard, than internal standardisation can be utilised yielding equation 2 . 


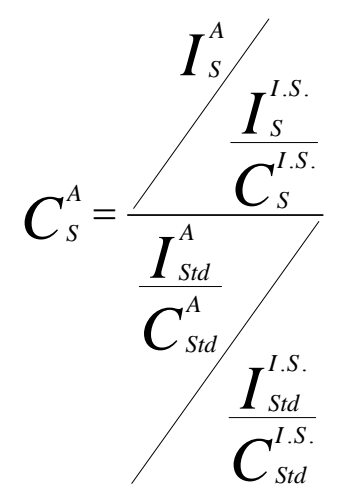

\section{Equation 2}

Calibration was performed using sample and standard discs produced from 100\% CRMs, and from sample and standard discs produced from 60\% CRM and 40\% PVA or vanillic acid binder. Different combinations of discs were used as sample and external standard and the quality of data compared to determine the effects of the presence of the vanillic acid organic chromophore, in particular whether utilising vanillic acid offered an improvement in data quality over PVA or pure pressed sample/standard. These investigations were performed under both wet and dry plasma conditions to determine whether the use of wet plasma conditions offers any advantage with respect to standardising plasma conditions as observed in previous work. ${ }^{52}$

Another set of calibrations were performed involving the use of a sample and a standard that were totally different in terms of their matrix composition. NIST 8435 Whole Milk Powder CRM was employed as either sample or standard with the other soil and sediment CRMs used previously. Again vanillic acid and PVA were used as a binder. This type of calibration was performed solely to verify the advantages offered by employing an absorbing binder, it is recognised that this deliberate 'mismatching' of sample and standard would not be employed for the analysis of a real sample. This series of calibrations were performed utilising 'dry' plasma conditions only.

It should be noted that for analysis of a 'real' sample, an internal standard element would normally be employed to correct for differences in ablation rates between the sample and the standard. In this investigation, the relative data quality between calibration sets, without internal standardisation, was more important than the absolute data quality with internal standardisation, to show the differences between the binders. However, since CRMs have been used as both samples and standards, then an internal standard element was available. For this reason, data utilising ${ }^{65} \mathrm{Cu}$ as 
an internal standard element is also presented and is useful in providing a comparison of the data quality obtainable by this method. 


\section{Results and Discussion}

\section{Homogeneity Trials}

The elemental distributions across the discs produced using the ball mixer were much more homogenous when compared to those produced using a simple pestle and mortar. This can be seen in Figure 4 and is numerically indicated by the much smaller \%RSDs obtained for those discs as highlighted in Table 4. Importantly, discs produced from 100\% CRM, with no subsequent homogenising stage, also showed poor homogeneity, indicating the importance of using a homogenising mixer mill even when no binder is employed, since the CRMs may not be as homogenous as is often assumed.

It is vital that the distribution of analyte within the discs is homogenous in order to obtain accurate and precise quantitative data. Using the 'absorbing binders' it is also necessary to ensure that the sample and binder has been adequately mixed, prior to pressing to facilitate an efficient coupling of the laser beam energy and the sample surface. It has been shown in this investigation that the use of a mixer mill is essential to provide a sufficient degree of mixing between sample and binder. All further discs employed in this investigation were therefore prepared using the mixer mill method rather than the pestle and mortar which produced an inadequate degree of mixing.

\section{Effect of Varying Disc Composition}

\section{LA-ICP-MS Analysis}

The use of vanillic acid as a binder led to increased sensitivity in comparison to the other binders investigated, as indicated by the steep climb and the high optimum of the curve in Figure 5 (although Figure 5 uses ${ }^{238} \mathrm{U}$ as the analyte, all the analytes investigated, see the list in Table 2, gave the same result). Vanillic acid was followed by pyrazinoic acid and nicotinic acid in terms of overall sensitivity.

This correlated with the molar absorptivities of the compounds quoted in Table 1, in which vanillic acid is shown to possess a greater molar absorptivity when compared 
to pyrazinoic and nicotinic acid. Importantly, all three 'absorbing binders' showed a gain in sensitivity when compared to the use of 'non-absorbing' PVA.

The absorbing binders, vanillic acid, nicotinic acid and pyrazinoic acid, yielded distinct curves with optima around 60 - 80\% CRM composition. Significantly, analysis of the series of discs produced using PVA yielded a straight line $\left(\mathrm{R}^{2}=\right.$ 0.9994), as for a regular external calibration, rather than a curve, indicating the absence of any optical absorbance effect.

\section{Diffuse Reflectance Analysis}

The diffuse reflectance data obtained are shown in Figure 6. The occurrence of the distinct curves can be related to the optical properties of the binders employed. When an 'absorbing binder' was employed, as the concentration of sample, and consequently analyte, was increased there was a subsequent decrease in the absorbance of the sample surface (indicated by an increase in \% reflectance) due to a reduction in absorbing binder concentration. There is a crossover point for the curves obtained from the analysis of pyrazinoic and nicotinic acid; as yet no explanation can be given, although it was observed that after pressing a pink tinge was often present on the surface of discs produced from pyrazinoic acid, indicating the occurrence of some unusual surface effects. Importantly, the data for PVA showed a slight decrease in reflectance as the sample concentration was increased, due to the fact that in this case the sample, GBW 07311 Sediment, had a greater absorptivity than the binder, PVA.

The diffuse reflectance data followed the same trend as the quoted molar absorptivities of the compounds, and the LA-ICP-MS data described previously. Vanillic acid offered the greatest absorbance of the laser energy, followed by pyrazinoic and nicotinic acid. As expected, PVA has been shown to possess the lowest optical absorbance at the lasing wavelength and showed a greater degree of reflectance than the pure sample. 


\section{Surface Profiling}

Surface profiling of the laser ablated tracks showed that, as expected, ablation produced shallower craters in more absorbing matrices. These data are shown in

Table 6. The depth of the craters produced correlated with the LA-ICP-MS and diffuse reflectance data already reported, in that the shallowest craters were produced in the most absorbing substrate, the vanillic acid. The deepest craters were produced in the least absorbing substrate, the PVA, as expected. The crater depths indicate directly the depth of penetration of the laser beam before its intensity falls below the threshold intensity for ablation. Nicotinic acid and pyrazinoic acid gave similar, relatively shallow crater depths, indicating that they offer a similar optical penetration depth.

It would have been interesting to characterise the shape and maximum depth of the craters produced in discs containing sample rather than just the binders. However, access to the surface profiling instrumentation was restricted, and it was felt that that it was most important to characterise the craters produced in the four binders used.

Although the greatest volume/mass of substrate was removed for the non-absorbing binder, the highest analytical sensitivity was obtained from the smallest crater volumes. The increased sensitivity offered by using an 'absorbing binder', such as vanillic acid, was almost certainly due to the production of smaller sized particles at the ablation site. Such smaller particles were more efficiently transported to, and processed by the ICP. Recent studies have shown that small particles are not necessarily produced directly from the laser/solid interaction, but more likely through secondary processes, namely by condensation of vaporised material. ${ }^{41-43}$ Nevertheless, a highly absorbing substrate results in a thinner melt layer and lower penetration depth, which in turn produces an aerosol with smaller particle sizes, and importantly an absence of larger particles that are not efficiently transported and processed by the plasma. Importantly, the generation of smaller particles during the ablation process is likely to reduce elemental fractionation occurring within the ICP which may be caused by selective volatilisation from the surface of large particles that are not fully vaporised. Therefore, the use of these absorbing binders should contribute to minimising the detrimental effects of elemental fractionation on quantitative analysis 
by LA-ICP-MS, as well as providing the more obvious benefits offered by increased sensitivity.

\section{Calibration and Analysis}

The data obtained under 'dry' plasma conditions are shown in Table 7. The recoveries were consistently closer to $100 \%$ when vanillic acid was used as a binder, compared to the use of a less absorbing binder or no binder at all. This outcome was true for all the elements studied with no outliers. When employing the vanillic acid, all external cross-calibrations resulted in recoveries well within $\pm 10 \%$. This was due to the chromophore dominating the ablation process rather than the sample. Unlike simple dilution of the sample, this 'active substrate' dilution/matrix matching enhanced sensitivity rather than reduced it. Vanillic acid yielded a signal response that was three times greater than when PVA was used.

External cross-calibration using discs of $100 \%$ CRM resulted in a broad range of recoveries (47 - 199\%), indicating that the differences in sample matrix had large effects on the quality of data obtained. It is well documented that even small changes in sample matrix can lead to large variations in ablation rates and hence the poor quality data obtained by this type of cross-calibration was hardly surprising.

When the non-absorbing PVA was employed as a binder, the quality of the data declined even further and a larger range of recoveries was obtained (47 - 219\%). This can probably be attributed to the dilution of the sample resulting in reduced sensitivity, since unlike vanillic acid, PVA does not offer an increase in target absorbance. This reduction in sensitivity meant that many analytes in the discs were at levels closer to their detection limits where the quality of analytical data was poorer.

The fact that an absorbing binder such as vanillic acid does offer an advantage over the use of a non absorbing binder, such as PVA, was confirmed by the repeat of the analyses under wet plasma conditions. Table 8 shows that the calculated recoveries were much closer to $100 \%$ when vanillic acid was used rather than PVA or no binder at all. 
The quality of the analytical data obtained under wet and dry plasma conditions showed no significant differences. The recoveries were perhaps slightly better under wet plasma conditions, but the differences were not large enough to confirm the merits of employing a wet plasma for this type of calibration. Unlike previous work, ${ }^{52}$ the determining factor in this investigation was the difference in sample and standard matrix, resulting in variations in ablation yields during the ablation process and not during the vaporisation and ionisation processes occurring within the plasma i.e. plasma processes were secondary to the primary ablation processes. Here, by using a standardised and strongly absorbing matrix, the total plasma loading did not vary as much between samples and standards as when a dried nebuliser derived aerosol is used to calibrate the response from a laser ablated solid substrate (water is needed in this case to produce a single dominant plasma species).

The advantages of employing an absorbing binder are emphasised in 
Table 9, which shows the analytical data obtained by using a sample and standard that differed greatly in terms of matrix composition. Once again the vanillic acid binder yielded a considerable improvement in data over that obtained from the use of discs produced from 100\% CRM and those produced using PVA as a binder.

Table 10 and Table 11 show the data obtained when ${ }^{65} \mathrm{Cu}$ was employed as an internal standard element. There was a vast improvement in the quality of the analytical data from the calibrations performed using discs produced from 100\% CRM and those produced from $40 \%$ PVA. This improvement is expected since the use of ${ }^{65} \mathrm{Cu}$ as an internal standard element corrects for differences in ablation rates between sample and standard, which would have been significant when utilising 100\% CRM or the PVA due to differences in target matrix. The quality of data did not improve for discs produced using vanillic acid since the standardised target matrix offered by these discs meant that rates of ablation were similar between sample and standard, and hence internal standard correction was not required. 


\section{Conclusion}

This work has shown that by utilising a binder that absorbs strongly at the lasing wavelength of $213 \mathrm{~nm}$, such as vanillic acid, rather than a non-absorbing binder such as PVA, excellent quality analytical data was obtained without the use of internal standardisation. By adding vanillic acid to the powdered sample of interest, an approximately three-fold gain in sensitivity was achieved over the use of PVA, leading to lower limits of detection and an improvement in quantitation. Importantly, the chromophores employed were successful as binders and produced discs of greater mechanical stability than by pressing the sample alone.

The data suggests that the mechanism for the increase in sensitivity was through the formation of smaller particles during the ablation process. Diffuse reflectance data showed that a greater absorptivity at the lasing wavelength was obtained by utilising vanillic acid as a binder. A greater absorption of the laser energy by the sample surface leads to a shorter effective penetration depth, as was shown by the surface profilometry. This allows a greater energy density to be achieved in the target, leading to the formation of smaller particles. Such particles are more efficiently transported to, and processed by the ICP, leading to an improvement in sensitivity and a reduction in plasma based elemental fractionation.

Employing vanillic acid as a binder introduces a degree of matrix matching between sample and standard, but more importantly, standardises the absorptivity of the matrix. This in turn leads to a standardisation of ablation conditions and mass flux to the plasma which are pre-requisites for robust calibration. Unlike the use of a traditional, non-absorbing binder, which simply dilutes the sample, this matrix matching is accompanied by an increase in sensitivity. The result is a substantial improvement in the quality of data obtained when using external calibration for LAICP-MS.

The use of absorbing chromophore binders has been shown to offer a robust calibration method for the quantitative analysis of powdered samples using simple external calibration. The data produced would be fit-for-purpose in many practical analytical applications. The technique is simple and employs commonly available laboratory reagents and equipment. 


\section{Acknowledgements}

This work was performed with financial backing from the Valid Analytical Measurements (VAM) Program and CERAM (Stoke-on-Trent, Staffordshire, UK). The authors would like to express their gratitude to Thermo Electron Corporation (Winsford, Cheshire, UK) for provision of the VG PQ ExCell ICP-MS instrument and LGC (Teddington, Middlesex, UK) who manage the VAM programme and provided the UP-213 LA system. Sincere thanks also to Jagpal Singh of the Metrology Department, Loughborough University, for the surface profiling. 


\section{References}

A. A. Vanheuzen, Spectrochimica Acta Part B-Atomic Spectroscopy, 1991, 46, 1803.

W. T. Perkins, R. Fuge, and N. J. G. Pearce, Journal of Analytical Atomic Spectrometry, 1991, 6, 445.

W. T. Perkins, N. J. G. Pearce, and R. Fuge, Journal of Analytical Atomic Spectrometry, 1992, 7, 611 .

W. T. Perkins, N. J. G. Pearce, and T. E. Jeffries, Geochimica Et Cosmochimica Acta, 1993, 57, 475.

J. S. Fedorowich, J. P. Richards, J. C. Jain, R. Kerrich, and J. Fan, Chemical Geology, 1993, 106, 229.

V. Kanicky and J. M. Mermet, Fresenius Journal of Analytical Chemistry, 1999, 363, 294.

C. A. Craig, K. E. Jarvis, and L. J. Clarke, Journal of Analytical Atomic Spectrometry, 2000, 15, 1001.

D. Gunther, A. von Quadt, R. Wirz, H. Cousin, and V. J. Dietrich, Mikrochimica Acta, 2001, 136, 101.

C. Pickhardt, J. S. Becker, and H. J. Dietze, Fresenius Journal of Analytical Chemistry, 2000, 368, 173.

T. Mochizuki, A. Sakashita, H. Iwata, T. Kagaya, T. Shimamura, and P. Ir, Analytical Sciences, 1988, 4, 403.

N. Imai, Analytical Chimica Acta, 1990, 235, 381.

A. A. Vanheuzen and J. B. W. Morsink, Spectrochimica Acta Part B-Atomic Spectroscopy, 1991, 46, 1819.

E. R. Denoyer, K. J. Fredeen, and J. W. Hager, Analytical Chemistry, 1991, 63, 445.

K. E. Jarvis and J. G. Williams, Chemical Geology, 1993, 106, 251.

C. D. Garbeschonberg and G. M. McMurtry, Fresenius Journal of Analytical Chemistry, 1994, 350, 264.

H. Cousin and B. Magyar, Mikrochimica Acta, 1994, 113, 313.

D. Gunther, H. Cousin, B. Magyar, and I. Leopold, Journal of Analytical Atomic Spectrometry, 1997, 12, 165. 

2000, 367, 635.

A. Raith and R. C. Hutton, Fresenius Journal of Analytical Chemistry, 1994, 350, 242.

R. D. Evans, P. M. Outridge, and P. Richner, Journal of Analytical Atomic Spectrometry, 1994, 9, 985.

Y. L. Lee, C. C. Chang, and S. J. Jiang, Spectrochimica Acta Part B-Atomic Spectroscopy, 2003, 58, 523.

F. Boue-Bigne, B. J. Masters, J. S. Crighton, and B. L. Sharp, Journal of Analytical Atomic Spectrometry, 1999, 14, 1665.

K. K. K. Lam and W. T. Chan, Journal of Analytical Atomic Spectrometry, 1997, 12, 7.

J. S. Becker and H. J. Dietze, Fresenius Journal of Analytical Chemistry, 1999, 365, 429.

P. Weis, H. Beck, and D. Gunther, Analytical and Bioanalytical Chemistry, 2005, 381, 212.

M. Guillong and D. Gunther, Journal of Analytical Atomic Spectrometry, 2002, 17, 831 .

B. Hattendorf, C. Latkoczy, and D. Gunther, Analytical Chemistry, 2003, 75, 341A.

I. Horn, M. Guillong, and D. Gunther, Applied Surface Science, 2001, 182, 91.

I. Horn and D. Gunther, Applied Surface Science, 2003, 207, 144.

S. H. Jeong, O. V. Borisov, J. H. Yoo, X. L. Mao, and R. E. Russo, Analytical Chemistry, 1999, 71, 5123.

J. Koch, I. Feldmann, N. Jakubowski, and K. Niemax, Spectrochimica Acta Part B-Atomic Spectroscopy, 2002, 57, 975.

J. Koch, H. Lindner, A. von Bohlen, R. Hergenroder, and K. Niemax, Journal of Analytical Atomic Spectrometry, 2005, 20, 901.

J. Koch, A. von Bohlen, R. Hergenroder, and K. Niemax, Journal of Analytical Atomic Spectrometry, 2004, 19, 267.

H. R. Kuhn, M. Guillong, and D. Gunther, Analytical and Bioanalytical Chemistry, 2004, 378, 1069.

H. R. Kuhn and D. Gunther, Analytical Chemistry, 2003, 75, 747. 
H. R. Kuhn and D. Gunther, Journal of Analytical Atomic Spectrometry, 2004, 19, 1158 .

H. R. Kuhn, J. Koch, R. Hargenroder, K. Niemax, M. Kalberer, and D. Gunther, Journal of Analytical Atomic Spectrometry, 2005, 20, 894.

C. Liu, X. L. Mao, S. S. Mao, X. Zeng, R. Greif, and R. E. Russo, Analytical Chemistry, 2004, 76, 379.

J. H. Yoo, S. H. Jeong, X. L. Mao, R. Greif, and R. E. Russo, Applied Physics Letters, 2000, 76, 783.

K. Niemax, Fresenius J. Anal. Chem., 2001, 370, 332.

R. Hergenroder, Journal of Analytical Atomic Spectrometry, 2006, 21, 517.

R. Hergenroder, Spectrochimica Acta Part B-Atomic Spectroscopy, 2006, 61, 284.

R. Hergenroder, Journal of Analytical Atomic Spectrometry, 2006, 21, 505.

M. Broadhead, Atomic Spectroscopy, 1991, 12, 45.

M. Broadhead, R. Broadhead, and J. W. Hager, Atomic Spectroscopy, 1990, 11, 205.

B. Magyar, H. Cousin, and B. Aeschlimman, Analytical Proceedings, 1992, 29, 282.

T. Mochizuki, A. Sakashita, H. Iwata, Y. Ishibashi, and N. Gunji, Analytical Sciences, 1991, 7, 151.

M. Tibi and K. G. Heumann, Journal of Analytical Atomic Spectrometry, 2003, 18, 1076.

R. G. Akos Vertes, in 'Methods utilising low and medium irradiance', ed. R. G. Akos Vertes, Fred Adams, New York, 1993.

S. M. Eggins, L. P. J. Kinsley, and J. M. G. Shelley, Applied Surface Science, 1998, 129, 278.

D. Gunther and C. A. Heinrich, Journal of Analytical Atomic Spectrometry, 1999, 14, 1363.

C. O' Connor, B. L. Sharp, and P. Evans, Journal of Analytical Atomic Spectrometry, 2006, 21, 556. 


\section{Figures}<smiles>COc1cc(C(=O)O)ccc1O</smiles>

Vanillic acid<smiles>O=C(O)c1cnccn1</smiles>

Pyrazinoic acid<smiles>O=C(O)c1cccnc1</smiles>

Nicotinic acid

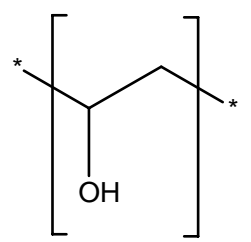

Poly(vinyl alcohol)

Figure 1 The molecular structures of the four binders investigated in this work.

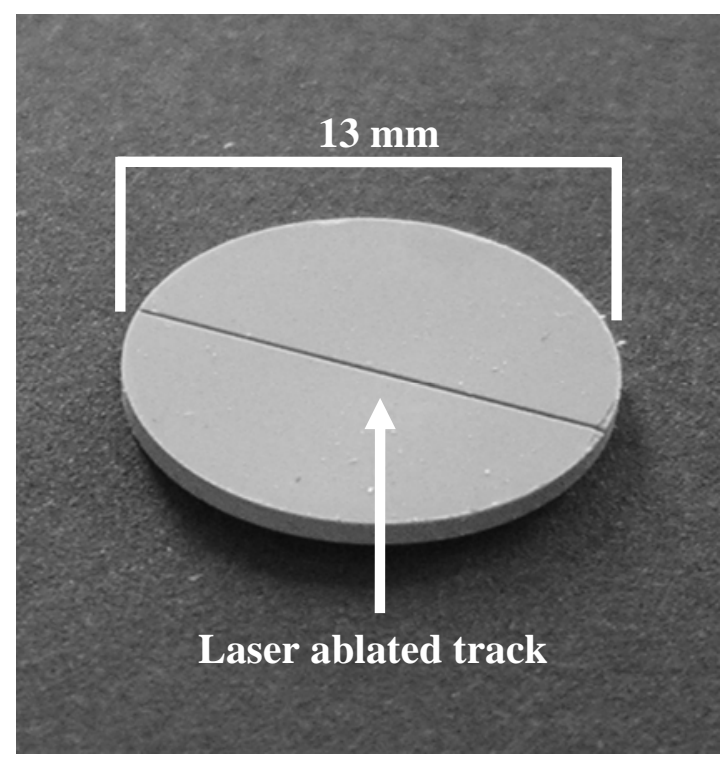

Figure 2 Digital photograph of a disc produced using vanillic acid as a binder and employing the mixer mill as a sample/binder mixing method. 


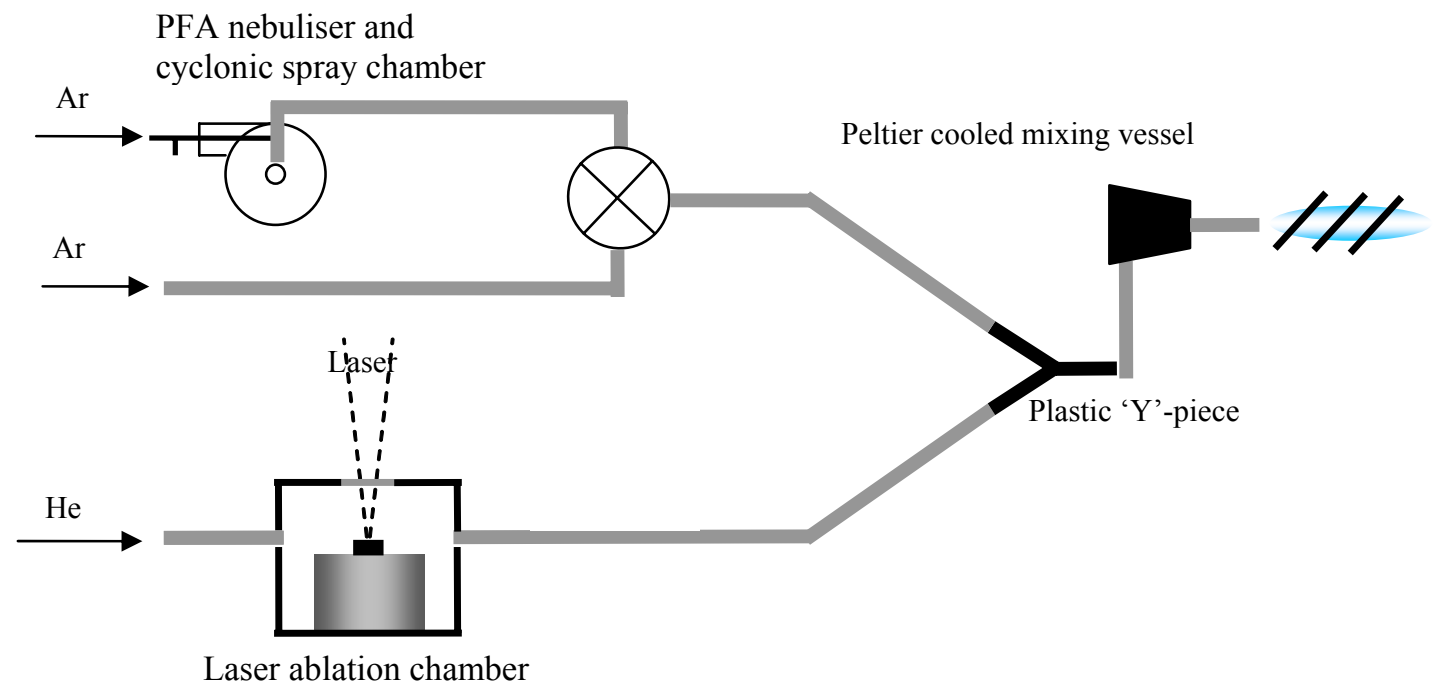

Figure 3 A schematic of the system used for LA-ICP-MS analysis. A PFA nebuliser and custom made cyclonic spray chamber was employed to produce wet plasma condition.

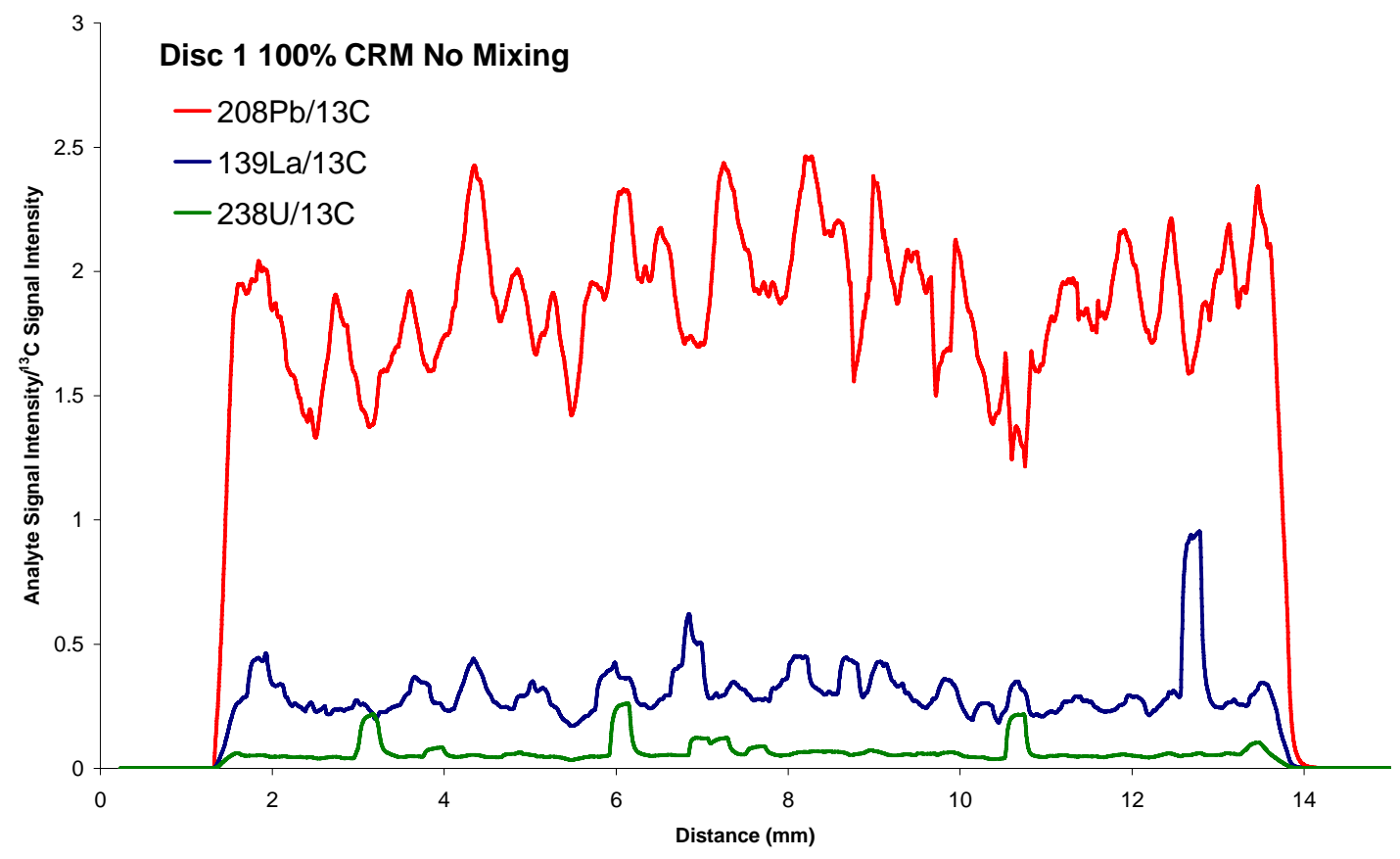



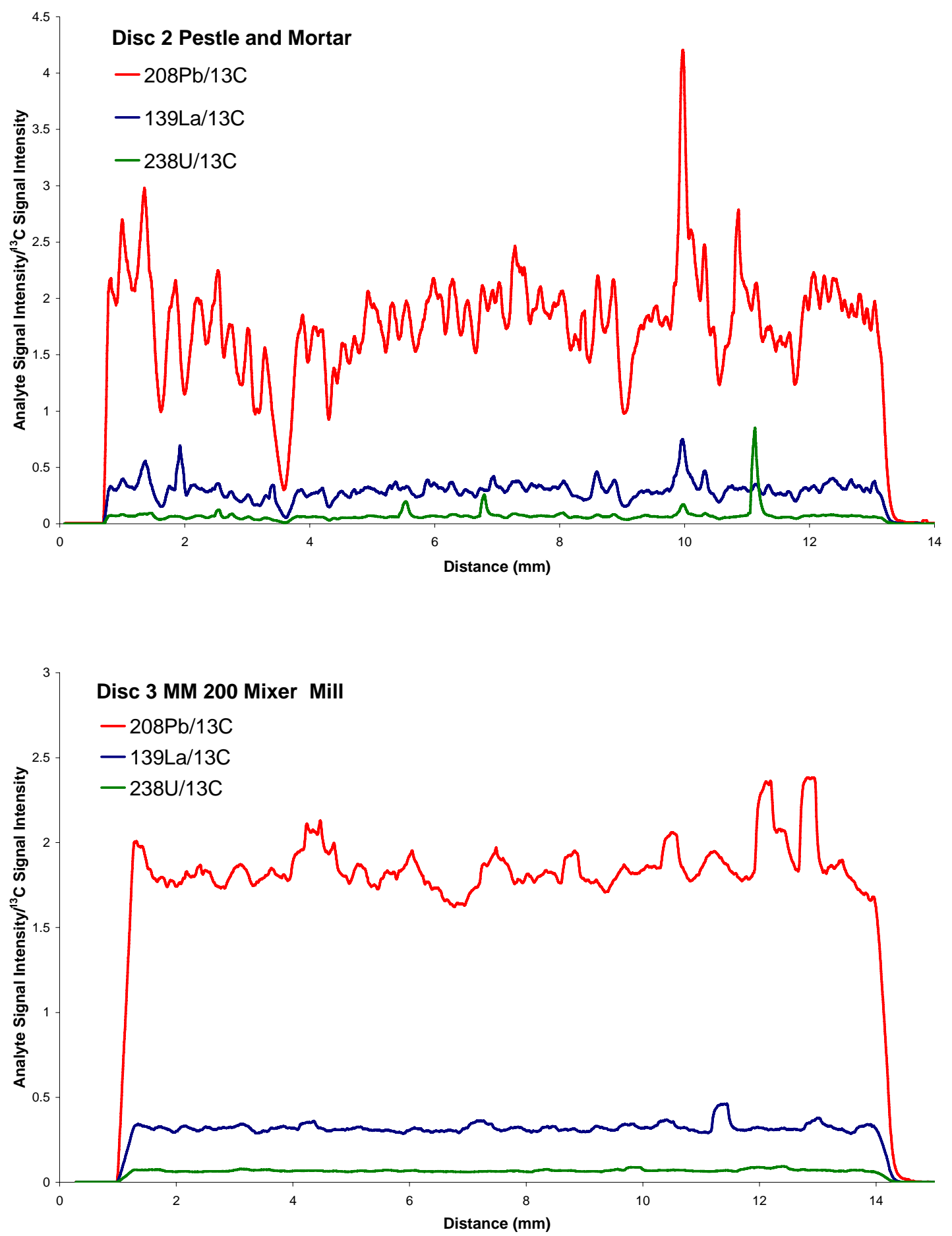

Figure 4 LA-ICP-MS analysis to determine the elemental distribution across discs: (1) produced from $100 \%$ sample, (2) $60 \%$ CRM and $40 \%$ vanillic acid binder mixed using a simple pestle and mortar, and (3) $60 \%$ CRM and 40\% vanillic acid binder mixed using a MM 200 mixer mill. CRM was GBW 07311 Sediment. 


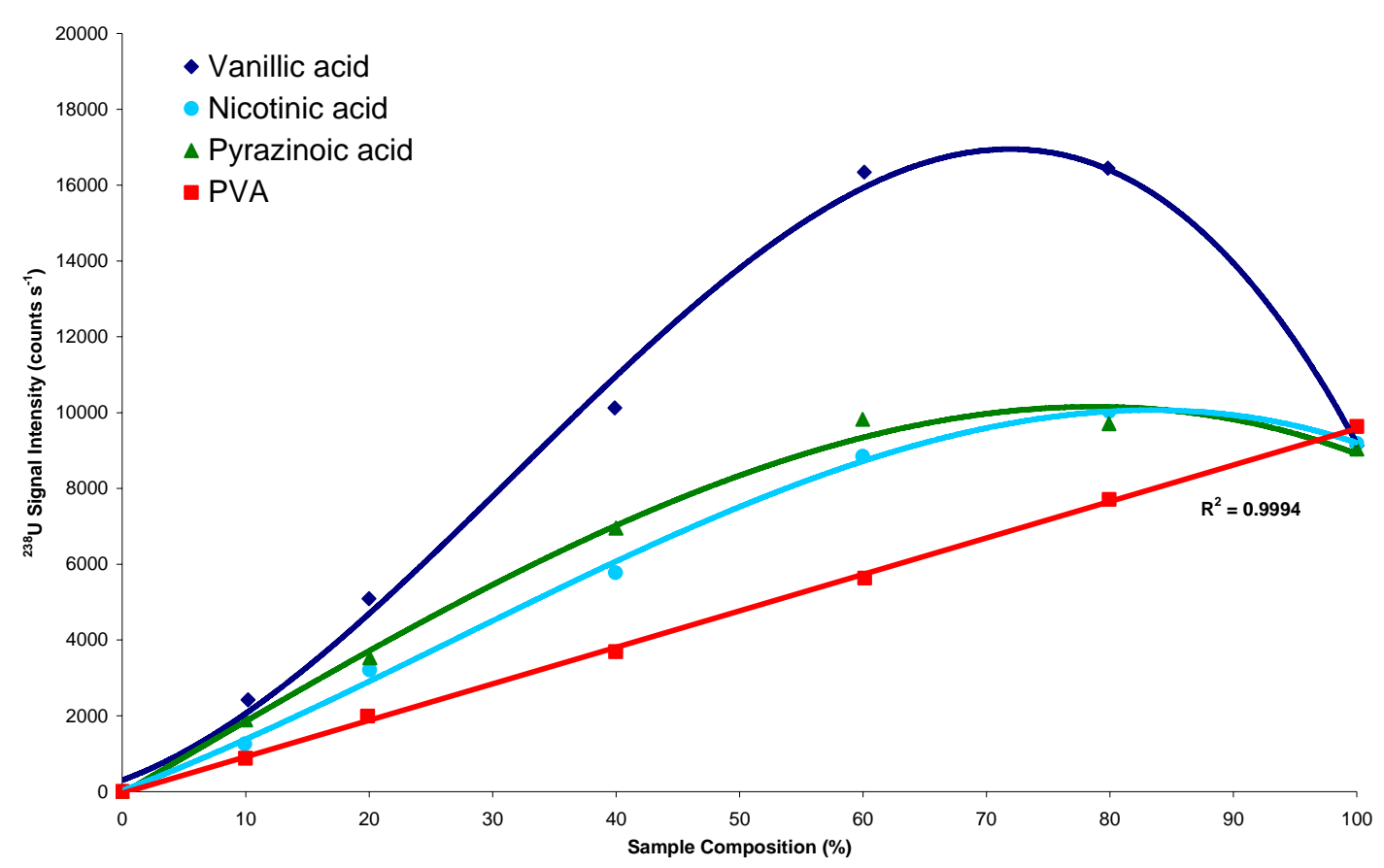

Figure 5 LA-ICP-MS data for discs produced using GBW 07311 Sediment as a sample and different binders of varying composition.

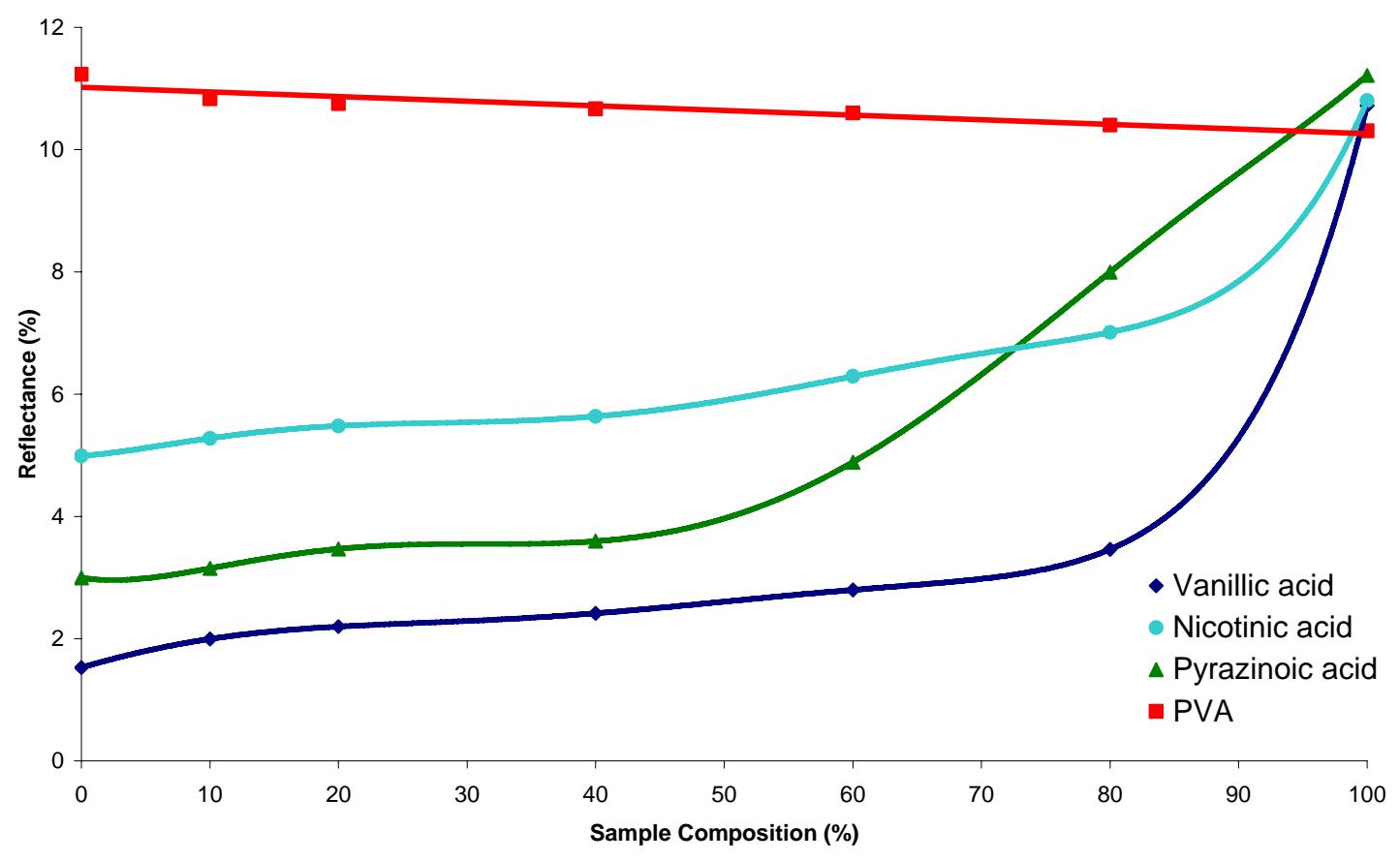

Figure 6 Reflectance data at $213 \mathrm{~nm}$ for discs produced using GBW 07311 Sediment as a sample and different binders of varying composition. 


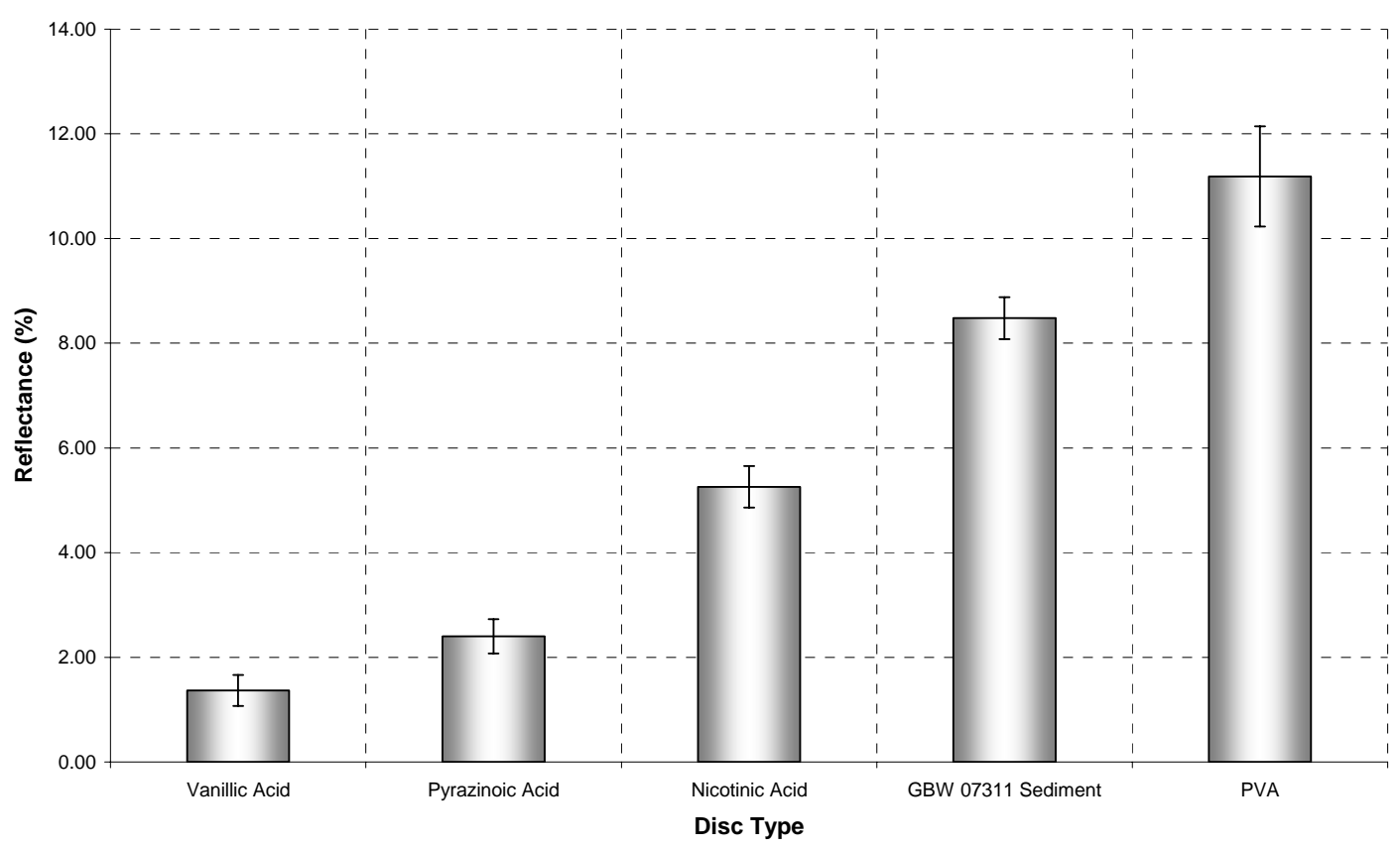

Figure 7 Reflectance data at $213 \mathrm{~nm}$ for discs produced from $100 \%$ of all the binders used in the investigation and of discs produced from 100\% GBW 07311 Sediment. Error bars are defined by one standard deviation either side of the mean. 


\section{Tables}

Table $1 \lambda_{\max }$ values and molar absorptivities for various binders used in this investigation. ${ }^{49}$

\begin{tabular}{|l|c|c|}
\hline Binder & $\lambda_{\max }(\mathrm{nm})$ & Molar absorptivity. $\varepsilon_{\max }\left(\mathrm{L} \mathrm{mol}^{-1} \mathrm{~cm}^{-1}\right)$ \\
\hline \hline Vanillic acid & 217 & 22900 \\
\hline Nicotinic acid & 217 & 8610 \\
\hline Pyrazinoic acid & 208 & 7960 \\
\hline
\end{tabular}

Table 2 Experimental parameters used for LA-ICP-MS measurements.

\begin{tabular}{|c|c|}
\hline \multicolumn{2}{|l|}{ Laser Ablation System } \\
\hline Type & Solid state Nd:YAG, UP-213 \\
\hline Wavelength & $213 \mathrm{~nm}$ \\
\hline Pulse duration & $4 \mathrm{~ns}$ \\
\hline Fluence & $2 \mathrm{~J} \mathrm{~cm}^{-2}$ \\
\hline Repetition rate & $20 \mathrm{~Hz}$ \\
\hline Sampling strategy & Raster \\
\hline Spot diameter & $110 \mu \mathrm{m}$ \\
\hline Sample translation rate & $10 \mu \mathrm{m} \mathrm{s}^{-1}$ \\
\hline He carrier gas flow & $0.80 \mathrm{~L} \mathrm{~min}^{-1}$ \\
\hline \multirow[t]{2}{*}{ Ar make up flow } & $1.00 \mathrm{~L} \mathrm{~min}^{-1}$ \\
\hline & Poly(vinyl alcohol) (PVA) \\
\hline \multirow{4}{*}{ Binders } & Vanillic acid \\
\hline & Nicotinic acid \\
\hline & Pyrazinoic acid \\
\hline & IMEP 14 Sediment CRM \\
\hline \multirow{3}{*}{ Samples } & GBW 07311 Sediment CRM \\
\hline & GBW 07401 Soil CRM \\
\hline & NIST 8435 Trace Elements in Powdered Milk CRM \\
\hline \multicolumn{2}{|r|}{ 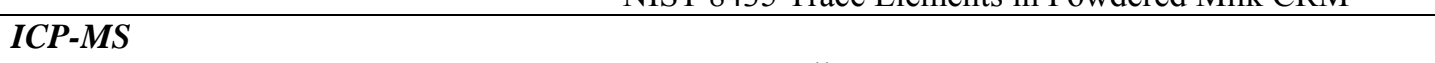 } \\
\hline Type & VG PQ ExCell \\
\hline Auxiliary gas flow & $0.80 \mathrm{~L} \mathrm{~min}^{-1}$ \\
\hline Cooling gas flow & $12.00 \mathrm{~L} \mathrm{~min}^{-1}$ \\
\hline Plasma RF power & $1400 \mathrm{~W}$ \\
\hline Isotopes monitored & $\begin{array}{l}{ }^{13} \mathrm{C},{ }^{47} \mathrm{Ti},{ }^{52} \mathrm{Cr},{ }^{55} \mathrm{Mn},{ }^{59} \mathrm{Co},{ }^{65} \mathrm{Cu},{ }^{66} \mathrm{Zn},{ }^{107} \mathrm{Ag},{ }^{111} \mathrm{Ag},{ }^{137} \mathrm{Ba}, \\
{ }^{139} \mathrm{La},{ }^{153} \mathrm{Eu},{ }^{166} \mathrm{Er},{ }^{205} \mathrm{Tl},{ }^{206} \mathrm{~Pb},{ }^{238} \mathrm{U}\end{array}$ \\
\hline Acquisition mode & Peak hopping \\
\hline Detector mode & Dual range \\
\hline Channels per peak & 1 \\
\hline Dwell time & $100 \mathrm{~ms}$ \\
\hline No. of sweeps & 100 \\
\hline No. of replicates & 50 \\
\hline \multicolumn{2}{|l|}{ Solution Nebulisation } \\
\hline Nebuliser & PFA- $100 \mu \mathrm{L}$ fixed capillary \\
\hline Spray chamber & Custom made cyclonic \\
\hline \multicolumn{2}{|l|}{ Diffuse Reflectance } \\
\hline Spectrometer & USB 2000 \\
\hline Light Source & DH 2000 \\
\hline Reflectance probe & R400-7-SR-BX \\
\hline Probe holder & RPH-1 Probe holder \\
\hline Integration time & $1 \mathrm{~s}$ \\
\hline Spectra average & 5 \\
\hline Reflectance Standard & WS-1 Diffuse Reflectance Standard (PTFE) \\
\hline Replicates & 5 \\
\hline
\end{tabular}




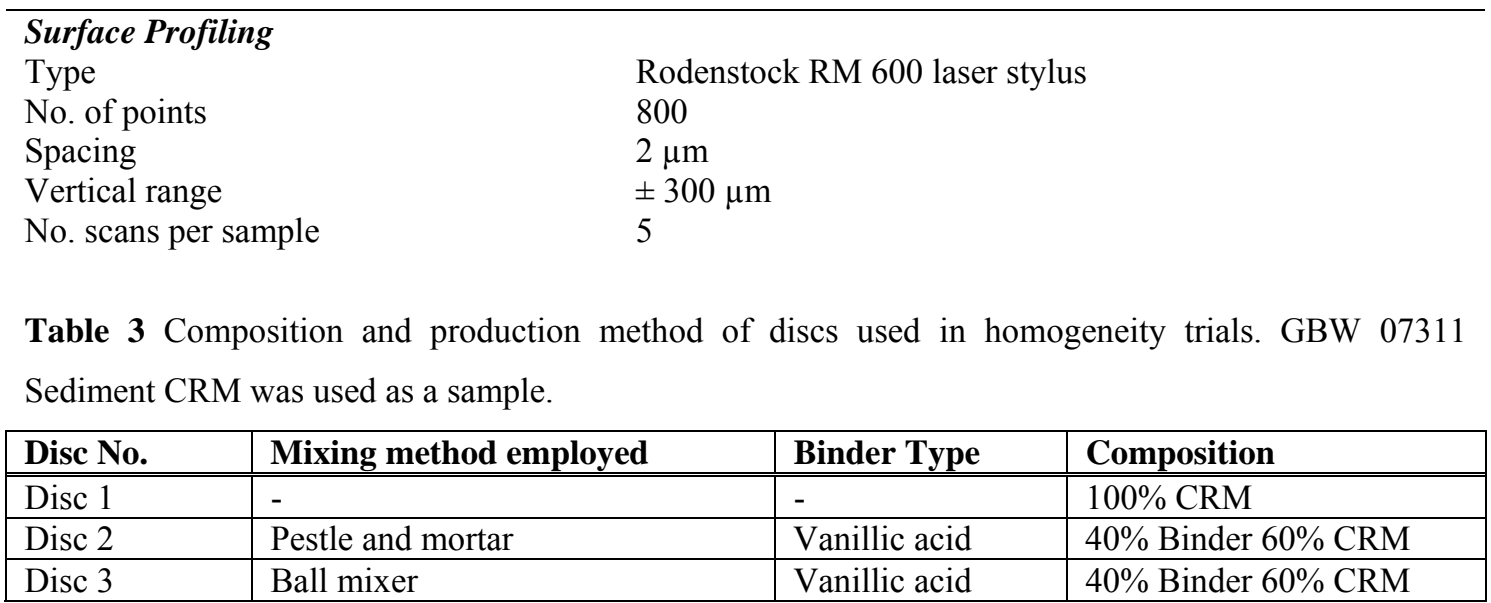

Table $4 \%$ RSDs of (analyte signal intensity $/{ }^{13} \mathrm{C}$ signal intensity) ratio for discs 1-3. Discs 2 and 3 were prepared using a $60 \% \mathrm{CRM}$ and $40 \%$ vanillic acid binder mixture.

\begin{tabular}{|l|c|c|c|c|}
\hline & \multicolumn{3}{|c|}{ \%RSD of (Analyte Signal Intensity/ ${ }^{\mathbf{1 3}}$ C Signal Intensity) } \\
\hline \hline Type & ${ }^{\mathbf{1 3 9}}$ La & ${ }^{208} \mathbf{P b}$ & ${ }^{\mathbf{2 3}} \mathbf{U}$ & Mean \%RSD \\
\hline \hline Disc 1 100\% CRM & 44 & 27 & 127 & $\mathbf{6 6}$ \\
\hline Disc 2 Pestle and Mortar & 39 & 29 & 117 & $\mathbf{6 2}$ \\
\hline Disc 3 Retsch MM 200 & $\mathbf{2 6}$ & $\mathbf{1 3}$ & $\mathbf{2 6}$ & $\mathbf{2 2}$ \\
\hline
\end{tabular}

Table 5 Reflectance data at $213 \mathrm{~nm}$ for discs produced from 100\% of all the binders used in the investigation of discs produced from 100\% GBW 07311 Sediment.

\begin{tabular}{|l|c|c|c|}
\hline Disc & Mean \%Reflectance & Standard Deviation & \%RSD \\
\hline \hline Vanillic acid & 1.37 & 0.30 & 22.70 \\
\hline Pyrazinoic acid & 2.40 & 0.33 & 8.68 \\
\hline Nicotinic acid & 5.26 & 0.40 & 7.57 \\
\hline GBW 07311 Sediment & 8.48 & 0.40 & 4.72 \\
\hline PVA & 11.19 & 0.96 & 8.58 \\
\hline
\end{tabular}

Table 6 Maximum crater depth measurements for discs produced from each of the four binders, obtained using surface profilometry.

\begin{tabular}{|c|c|c|c|c|c|c|c|c|}
\hline & \multicolumn{6}{|c|}{ Maximum Crater Depth $(\mu \mathrm{m})$} & \multirow[b]{2}{*}{$\mathrm{SD}$} & \multirow[b]{2}{*}{$\%$ RSD } \\
\hline Disc & 1 & 2 & 3 & 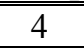 & 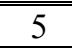 & Mean & & \\
\hline Vanillic acid & 86 & 93 & 81 & 87 & 86 & 87 & 4.2 & 4.8 \\
\hline Nicotinic acid & 96 & 86 & 91 & 105 & 108 & 97 & 9.4 & 9.7 \\
\hline Pyrazinoic acid & 91 & 102 & 104 & 98 & 98 & 98 & 5.1 & 5.2 \\
\hline PVA & 137 & 152 & 148 & 127 & 109 & 135 & 17.3 & 12.9 \\
\hline
\end{tabular}

Table 7 Analytical data showing the mean and \%RSD recoveries using different combinations of discs as sample and standard. The data were obtained under 'dry' plasma conditions. The title ' $\mathrm{n}=$ ' represents the number of analytes quantified per calibration. IMEP 14 and GBW 07311 are sediments whilst GBW 07401 is a soil.

\begin{tabular}{|l|l|c|c|c|c|c|c|c|}
\cline { 3 - 9 } \multicolumn{2}{c|}{} & \multicolumn{2}{c|}{$\begin{array}{c}\text { Recovery Data } \\
100 \% \text { CRM (\%) }\end{array}$} & \multicolumn{2}{c|}{$\begin{array}{c}\text { Recovery Data } \\
40 \% \text { PVA (\%) }\end{array}$} & \multicolumn{2}{c|}{$\begin{array}{c}\text { Recovery Data } \\
40 \% \text { Vanillic (\%) }\end{array}$} & RSD \\
\hline \hline Sample & Standard & Mean & RSD & Mean & RSD & Mean & RS \\
\hline \hline IMEP 14 & GBW 07311 & 199 & 25 & 219 & 20 & $\mathbf{9 2}$ & $\mathbf{1 2}$ & 6 \\
\hline GBW 07401 & GBW 07311 & 110 & 20 & 149 & 53 & $\mathbf{1 0 9}$ & $\mathbf{1 2}$ & 15 \\
\hline
\end{tabular}




\begin{tabular}{|c|l|c|c|c|c|c|c|c|}
\hline GBW 07311 & IMEP 14 & 53 & 15 & 47 & 20 & $\mathbf{1 0 4}$ & $\mathbf{2 3}$ & 6 \\
\hline GBW 07401 & IMEP 14 & 47 & 11 & 72 & 60 & $\mathbf{1 1 0}$ & $\mathbf{1 3}$ & 6 \\
\hline GBW 07311 & GBW 07401 & 89 & 20 & 132 & 170 & $\mathbf{9 6}$ & $\mathbf{9}$ & 15 \\
\hline IMEP14 & GBW 07401 & 222 & 49 & 164 & 32 & $\mathbf{9 2}$ & $\mathbf{1 3}$ & 6 \\
\hline \multicolumn{2}{|c|}{ Mean } & $\mathbf{1 2 0}$ & $\mathbf{2 3}$ & $\mathbf{1 3 1}$ & $\mathbf{5 9}$ & $\mathbf{1 0 1}$ & $\mathbf{1 4}$ & \\
\hline Standard deviation & $\mathbf{7 4}$ & - & $\mathbf{6 3}$ & - & $\mathbf{8}$ & - \\
\hline \multicolumn{2}{|c|}{ \%SD } & $\mathbf{6 2}$ & - & $\mathbf{4 8}$ & - & $\mathbf{8}$ & - \\
\hline
\end{tabular}

Table 8 Analytical data showing the mean and \%RSD recoveries using different combinations of discs as sample and standard. The data were obtained under 'wet' plasma conditions. The title ' $n=$ ' represents the number of analytes quantified per calibration. IMEP 14 and GBW 07311 are sediments whilst GBW 07401 is a soil.

\begin{tabular}{|c|c|c|c|c|c|c|c|c|}
\hline \multirow[b]{2}{*}{ Sample } & \multirow[b]{2}{*}{ Standard } & \multicolumn{2}{|c|}{$\begin{array}{c}\text { Recovery Data } \\
100 \% \text { CRM (\%) }\end{array}$} & \multicolumn{2}{|c|}{$\begin{array}{l}\text { Recovery Data } \\
40 \% \text { PVA }(\%)\end{array}$} & \multicolumn{2}{|c|}{$\begin{array}{c}\text { Recovery Data } \\
40 \% \text { Vanillic }(\%)\end{array}$} & \multirow[b]{2}{*}{$\mathbf{n}=$} \\
\hline & & Mean & RSD & Mean & RSD & Mean & RSD & \\
\hline IMEP 14 & GBW 07311 & 177 & 17 & 183 & 19 & 93 & 10 & 6 \\
\hline GBW 07401 & GBW 07311 & 115 & 23 & 125 & 55 & 110 & 12 & 15 \\
\hline GBW 07311 & IMEP 14 & 69 & 15 & 49 & 20 & 104 & 24 & 6 \\
\hline GBW 07401 & IMEP 14 & 59 & 18 & 75 & 55 & 111 & 15 & 6 \\
\hline GBW 07311 & GBW 07401 & 92 & 24 & 130 & 71 & 98 & 7 & 15 \\
\hline IMEP14 & GBW 07401 & 174 & 37 & 149 & 41 & 94 & 11 & 6 \\
\hline \multicolumn{2}{|c|}{ Mean } & 114 & 22 & 119 & 44 & 102 & 13 & \\
\hline \multicolumn{2}{|c|}{ Standard deviation } & 51 & & 49 & & 8 & & \\
\hline \multicolumn{2}{|c|}{ \%RSD } & 45 & & 41 & & 8 & & \\
\hline
\end{tabular}


Table 9 Analytical data showing the mean and \%RSD recoveries using different combinations of discs as sample and standard. In this case the sample and standard were deliberately chosen to differ in terms of their matrix composition. IMEP 14 and GBW 07311 are sediments, GBW 07401 is a soil, whilst NIST 8435 is a powdered milk. The data were obtained under 'dry' plasma conditions. The title ' $\mathrm{n}=$ ' represents the number of analytes quantified per calibration.

\begin{tabular}{|l|l|c|c|c|c|c|c|c|}
\cline { 3 - 9 } \multicolumn{2}{c|}{} & \multicolumn{2}{c|}{$\begin{array}{c}\text { Recovery Data } \\
100 \% \text { CRM (\%) }\end{array}$} & \multicolumn{2}{c|}{$\begin{array}{c}\text { Recovery Data } \\
40 \% \text { PVA }\end{array}$} & \multicolumn{2}{c|}{$\begin{array}{c}\text { Recovery Data } \\
40 \% \text { Vanillic (\%) }\end{array}$} & n= \\
\hline \hline Sample & Standard & Mean & RSD & Mean & RSD & Mean & RSD & n= \\
\hline \hline NIST 8435 & GBW 07311 & 286 & 51 & 291 & 55 & $\mathbf{1 5 8}$ & $\mathbf{1 6}$ & 5 \\
\hline NIST 8435 & GBW 07401 & 314 & 44 & 294 & 53 & $\mathbf{1 6 5}$ & $\mathbf{1 6}$ & 5 \\
\hline NIST 8435 & IMEP 14 & 232 & 111 & 212 & 98 & $\mathbf{1 6 6}$ & $\mathbf{1 2}$ & 4 \\
\hline GBW 07311 & NIST 8435 & 41 & 40 & 40 & 53 & $\mathbf{6 6}$ & $\mathbf{2 0}$ & 5 \\
\hline GBW 07401 & NIST 8435 & 36 & 34 & 33 & 44 & $\mathbf{6 8}$ & $\mathbf{1 5}$ & 5 \\
\hline IMEP 14 & NIST 8435 & 78 & 55 & 61 & 62 & $\mathbf{7 2}$ & $\mathbf{1 4}$ & 4 \\
\hline \hline
\end{tabular}

Table 10 Analytical data, using ${ }^{65} \mathrm{Cu}$ as an internal standard element, showing the mean and \%RSD recoveries using different combinations of discs as sample and standard. The data were obtained under 'dry' plasma conditions. The title ' $n=$ ' represents the number of analytes quantified per calibration. IMEP 14 and GBW 07311 are sediments whilst GBW 07401 is a soil.

\begin{tabular}{|l|l|c|c|c|c|c|c|c|}
\cline { 3 - 9 } \multicolumn{2}{c|}{} & \multicolumn{2}{c|}{$\begin{array}{c}\text { Recovery Data } \\
100 \% \text { CRM (\%) }\end{array}$} & \multicolumn{2}{c|}{$\begin{array}{c}\text { Recovery Data } \\
40 \% \text { PVA }(\%)\end{array}$} & \multicolumn{2}{c|}{$\begin{array}{c}\text { Recovery Data } \\
40 \% \text { Vanillic (\%) }\end{array}$} & \\
\hline \hline Sample & Standard & Mean & RSD & Mean & RSD & Mean & RSD & n= \\
\hline \hline IMEP 14 & GBW 07311 & 86 & 20 & 82 & 20 & $\mathbf{9 2}$ & $\mathbf{2 2}$ & 5 \\
\hline GBW 07401 & GBW 07311 & 135 & 20 & 114 & 53 & $\mathbf{1 1 1}$ & $\mathbf{2 1}$ & 14 \\
\hline GBW 07311 & IMEP 14 & 124 & 19 & 126 & 19 & $\mathbf{1 1 7}$ & $\mathbf{2 4}$ & 5 \\
\hline GBW 07401 & IMEP 14 & 146 & 21 & 142 & 63 & $\mathbf{1 1 9}$ & $\mathbf{1 2}$ & 5 \\
\hline GBW 07311 & GBW 07401 & 76 & 19 & 105 & 46 & $\mathbf{9 3}$ & $\mathbf{1 7}$ & 14 \\
\hline IMEP14 & GBW 07401 & 71 & 18 & 85 & 36 & $\mathbf{8 5}$ & $\mathbf{1 3}$ & 5 \\
\hline \hline
\end{tabular}


Table 11 Analytical data, using ${ }^{65} \mathrm{Cu}$ as an internal standard element, showing the mean and \%RSD recoveries using different combinations of discs as sample and standard. In this case the sample and standard have been deliberately chosen to differ in terms of their matrix composition. IMEP 14 and GBW 07311 are sediments, GBW 07401 is a soil, whilst NIST 8435 is a powdered milk. The data were obtained under 'dry' plasma conditions. The title ' $n=$ ' represents the number of analytes quantified per calibration.

\begin{tabular}{|l|l|c|c|c|c|c|c|c|}
\cline { 3 - 9 } \multicolumn{2}{c|}{} & \multicolumn{2}{c|}{$\begin{array}{c}\text { Recovery Data } \\
100 \% \text { CRM (\%) }\end{array}$} & \multicolumn{2}{c|}{$\begin{array}{c}\text { Recovery Data } \\
40 \% \text { PVA (\%) }\end{array}$} & \multicolumn{2}{c|}{$\begin{array}{c}\text { Recovery Data } \\
40 \% \text { Vanillic (\%) }\end{array}$} & \\
\hline \hline Sample & Standard & Mean & RSD & Mean & RSD & Mean & RSD & n= \\
\hline \hline NIST 8435 & GBW 07311 & 108 & 58 & 103 & 54 & $\mathbf{1 2 0}$ & $\mathbf{2 6}$ & 4 \\
\hline NIST 8435 & GBW 07401 & 65 & 8 & 67 & 17 & $\mathbf{1 2 2}$ & $\mathbf{3 0}$ & 4 \\
\hline NIST 8435 & IMEP 14 & 93 & 24 & 92 & 29 & $\mathbf{1 1 7}$ & $\mathbf{1 2}$ & 3 \\
\hline GBW 07311 & NIST 8435 & 113 & 45 & 119 & 40 & $\mathbf{7 5}$ & $\mathbf{5 1}$ & 4 \\
\hline GBW 07401 & NIST 8435 & 121 & 41 & 120 & 41 & $\mathbf{8 7}$ & $\mathbf{3 0}$ & 4 \\
\hline IMEP 14 & NIST 8435 & 90 & 69 & 91 & 69 & $\mathbf{8 7}$ & $\mathbf{1 1}$ & 3 \\
\hline \hline
\end{tabular}

